\title{
Racial Differences Effects on Oral Health and Periodontal Diseases Extent, Staging and Grading among the Multi-Ethnic Expatriates in Aseer Region, Saudi Arabia
}

\author{
Mohammed M. A. Abdullah Al-Abdaly ${ }^{1 *}$, Sultan Mansour A. Alqahtani2, \\ Shaker Saleh M. Alosman², Ghadah Ali Saad Alqahtani2 \\ ${ }^{1}$ Periodontics and Community Dental Sciences Department, College of Dentistry, King Khalid University, Abha, Saudi Arabia \\ ${ }^{2}$ College of Dentistry, King Khalid University, Abha, Saudi Arabia \\ Email: *malabdaly20@gmail.com
}

How to cite this paper: Al-Abdaly, M.M.A.A., Alqahtani, S.M.A., Alosman, S.S.M. and Alqahtani, G.A.S. (2021) Racial Differences Effects on Oral Health and Periodontal Diseases Extent, Staging and Grading among the Multi-Ethnic Expatriates in Aseer Region, Saudi Arabia. International Journal of Clinical Medicine, 12, 145-164.

https://doi.org/10.4236/ijcm.2021.124015

Received: March 27, 2021

Accepted: April 18, 2021

Published: April 21, 2021

Copyright () 2021 by author(s) and Scientific Research Publishing Inc. This work is licensed under the Creative Commons Attribution International License (CC BY 4.0).

http://creativecommons.org/licenses/by/4.0/ (c) (i) Open Access

\begin{abstract}
Background: Given the increase in the numbers of expatriates in Saudi Arabia and the shortage of information about expatriates' oral health and periodontal disease severity and progression. Objectives: This study aimed to evaluate the effects of the racial differences on oral health and periodontal disease extent, staging, and grading among the multi-ethnic expatriates in the Aseer region, Saudi Arabia. Materials and Methods: This cross-sectional study was carried out on 300 expatriates in Aseer region, Saudi Arabia. They were divided into three equal racial different groups $(n=100)$, Arabs $(A R)$, Asians (AS), and Africans (AF). The interviews of all participants were completed then the clinical examinations of periodontal diseases extent, staging, and grading parameters were performed. Statistical analysis was done by ANOVA test, Tukey's test, and Chi-square test. The statistical significance level was determined at $\mathrm{p}<0.05$. Results: There were statistically significant differences in the comparison between the three ethnic/racial groups in clinical parameters except in GBI, PCR, FI, TFO, and BC, where there were no statistically significant differences in the comparison between the three ethnic/racial groups. There were differences associated with age, gender, smoking, and diabetes, without statistically significant differences among the three racial groups. Conclusion: We concluded that most participants in this study had a generalized severe grade 4 plaque-induced gingivitis and localized periodontitis stage III grade $\mathrm{B}$.
\end{abstract}

\section{Keywords}

Multi-Ethnics, Oral Health, Periodontal Diseases Extent, Staging and Grading 


\section{Introduction}

Oral health is necessary for public health and lifestyle. Consequently, Bad oral health maybe leads to difficulties eating or speaking and restrict daily life [1]. On the other hand, periodontal disease is a multifactorial inflammatory disease of the oral cavity that can be gingivitis confined only to the gingiva or periodontitis when exceeding the soft tissues and affects the hard tissues attachment of the teeth [2]. Periodontal disease affects $10 \%-15 \%$ of people worldwide. Thus, it has a high effect on general health [3].

Periodontal diseases occur in all age groups due to common etiological and other predisposing factors that, causing the initiation and progression of periodontal diseases [4] [5]. Comparable to other chronic diseases, periodontal disease is considered a complex disease, and patient behaviors, environmental factors, medication use, genetic and epigenetic influences establish periodontal disease development [6]. Periodontitis affecting on $13 \%$ to $57 \%$ of adult populations in the Arab World, and mild-to-moderate periodontitis is the most common form [7] [8] [9].

The races of patients also promote the individuals' predisposition to periodontal diseases [10]. Racial differences in periodontal diseases in the U.S. have been recognized, with African Americans and Mexican-Americans as more susceptible to periodontal diseases than other racial groups [11] [12], where the periodontal health among white people is better than other ethnic groups [13]. This may be due to the effect of race on income and education [14]. Thus, recognition of racial variations is a significant side to recognizing the people's oral and public health and planning suitable [15].

The self-identification of the races is a complex process that includes several factors: geographical, inherited, ethnic, and somatic characteristics, moreover the language, customs, religion, and culture. The racial groups differ in lifestyle, such as smoking and diet, alcohol consumption also their dental services. As well as the impacts of assimilation, expatriation, and discrimination, furthermore, environmental effects such as variations in personal- and region-based socioeconomic level and the racial blend of people [16] [17]. Former studies display that the racial variations in oral health linked by behavioral, cultural, socioeconomic factors, as well as access to dental services and there were high level of dental diseases and low level of oral care among expatriates in contrast with local-born [18] [19] [20] [21]. There are multi distinct races among the minority groups, and oral health troubles highly spread between them [22].

In Saudi Arabia, 30\% of the population is as expatriates from worldwide, and as far as we know, there is no study in the college of dentistry, King Khalid University, that displays the impact of racial differences on oral health and periodontal diseases extent, staging and grading among the multi-ethnic expatriates in Saudi Arabia. Therefore, the purpose of the present study is to evaluate oral health and periodontal status among expatriates from different racial origins in the Aseer region, Saudi Arabia. 


\section{Materials and Methods}

\subsection{Design of Study and Sample Size}

This retrospective descriptive study was done on 300 expatriate patients with periodontal diseases at the clinics of the college of dentistry, King Khalid University, from $1^{\text {st }}$ of October 2020 to the end of February 2021. The present study comprised three different race groups living in Saudi Arabia as group I (Arabs), group II (Asians), and group III (Africans). The three groups of the present study are all expatriates to Saudi Arabia recently (within the last 20 years). Consequently, they still in close connections with their origin countries, which can help them to resist alter behavior and beliefs. The sample size in the present study was determined to depend on a study conducted by Eke, et al. in 2012, a sample size of $n=300$ (100 per group) [12].

\subsection{Ethical Considerations and Ethics Approval}

Written informed consent gained. The participants in the present study were volunteers and received explanations about the nature of the study, then their written informed consent was obtained. Moreover, ethical approval was obtained from the institutional review board, the college of dentistry, King Khalid University (IRB/REG/2020-2021/75).

\subsection{Inclusion and Exclusion Criteria}

The participants with or without systemic disease are involved in this study. The main inclusion criteria for all participants in the current research that they should be non-Saudi, and they all should be from three different races according to the study design. Study participants without periodontal diseases and who received mechanical and chemical periodontal therapy excluded. We excluded the participants who did not clarify their ethnic group and mixed ethnic group to avoid the difficulty in the interpretation of the results due to the heterogeneity within these groups.

\subsection{Participants' Characteristics}

In this study, we determine race and gender as non-changeable factors, whereas oral health periodontal parameters, smoking, diabetes are grouped as changeable factors. The participants' characteristics as age, gender, and race were included in our assessment to investigate the effects of these factors on oral health and periodontal diseases extent, staging and grading. We checked the other characteristics of the participants, such as the presence of diabetes and smoking status. The age range of the participants was between $14-89$ years old.

\subsection{Clinical Examination}

The participants was interviewed and clinically examined by the researchers on the authority of to World Health Organization's (WHO) criteria [23]. Gingival 
bleeding index (GBI), plaque control record (PCR) recorded [24] [25]. Moreover, clinical attachment loss (CAL), percentage (\%) of bone loss (\%BL), number of teeth missing due to periodontal diseases (NMT), Periodontal pocket depth (PPD), Pattern of bone loss (PBL), tooth mobility (TM), furcation involvement (FI), present of trauma from occlusion (TFO), bite collapse (drifting, flaring) (BC) and less than 20 remaining teeth (10 opposing pairs).

Periodontal disease in the present study was determined, like gingival diseases and periodontitis. Gingival diseases include localized or generalized (mild or moderate or severe), grade 1 or 2 or 3 or 4 or 5 dental plaque-induced gingivitis. Moreover, periodontitis was diagnosed as localized and generalized, stage I, II, III, or IV periodontitis. Diabetic status was determined by the glycated hemoglobin (HbAlc) test. When HbAlc less than 7.0, it will be grade periodontitis grade $\mathrm{B}$, and when $\mathrm{HbAlc}$ of 7.0 or more, it will be periodontitis grade $\mathrm{C}$. The participants' smoking status was determined, as smokers and non-smokers. When the participant's smoking less than ten cigarettes daily, it will be, periodontitis grade $\mathrm{B}$, and when the participant's smoking ten cigarettes or more, it will be periodontitis grade C [26] [27].

\subsection{Radiographic Evaluation}

The alveolar radiographic bone loss in the current study evaluated as percentages of radiographic bone loss where we measured, in millimeters, the distance from the cement-enamel junction (CEJ) to the alveolar bone crest $(\mathrm{ABC})$ as well as the distance from CEJ to the root apex with the calibrated measuring tool of Emago (Oral Diagnostic Systems, Amsterdam, Netherlands) software-the radiographic imaging software at HSDM. Percentage bone loss is calculated by the difference between those distances multiplied by 100 [28]. The percentage of radiographic bone loss divided by the patient's age applied to the evaluation of periodontitis progression [29] [30].

\subsection{Glycosylated Hemoglobin (HbA1c) Assessment}

The medical reports of participants were used to identify glycosylated hemoglobin more or less than 7\%, and according to these reports, the test kit (A1cNow+) was used with a laboratory method (Ion Exchange Resin method) using a semi-auto analyzer [31].

\subsection{Statistical Analysis}

The age and clinical parameters of the participants of the three groups were compared using the ANOVA test. Whereas the comparison between group I and II and between III and I. Moreover, a comparison between groups II and III based on their age and clinical parameters conducted using Tukey's test. Chisquare test carried out to the comparison between groups II, III, and I in the participants' characteristics and clinical parameters. The statistical significance level was determined at $\mathrm{P}<0.05$. 


\section{Results}

The present study samples included 300 participants. There were 200 (66.7\%) males and 100 (33.3\%) females. They were divided into three equal groups Arabs (group I), Asians (group II), and Africans (group III). The ranges of ages for groups I, II\&III were $14-89$ ys, 21 - 76 ys, and 18 - 81 ys with means and standard deviations $( \pm \mathrm{SD}) 32.3 \pm 14.5 \mathrm{ys}, 42.96 \pm 12.7 \mathrm{ys}$, and $39.32 \pm 12.9$ ys, respectively. Consequently, the ages of Asian participants more than the ages of Arabs and Africans, and the participants' ages of Africans more than the participants' ages of Arabs, and there were highly statistically significant differences in the comparison of the participants' ages between Arabs, Asians and Africans, Arabs and Asians and Arabs and Africans, without statistically significant differences in the comparison of the participants' ages between Asians and Africans (Table 1 \& Figure 1).

On the other hand, $211(70.3 \%)$ of the total participants were non-smokers, 89 (29.7\%) were smokers, and 111 males (55.5\%) were non-smokers, and 89 males (44.5\%) were smokers, whereas all females were non-smokers. There no statistically significant differences in the present study between Arabs, Asians, and African participants in gender and smoking. Regarding number of cigarettes/day

Table 1. Age of participants.

\begin{tabular}{|c|c|c|c|c|}
\hline & \multicolumn{2}{|r|}{ Age } & \multicolumn{2}{|c|}{ ANOVA } \\
\hline & Range & Mean \pm SD & $\mathrm{F}$ & P-value \\
\hline Group I (AR) & $14-89$ & $32.3203 \pm 14.543$ & & \\
\hline Group II (AS) & $21-76$ & $42.9603 \pm 12.703$ & 16.253 & $<0.001^{\star}$ \\
\hline Group III (AF) & $18-81$ & $39.3203 \pm 12.9193$ & & \\
\hline \multicolumn{5}{|c|}{ Tukey's test } \\
\hline \multicolumn{2}{|c|}{ (I) AR \& (II) AS } & (I) $\mathrm{AR} \&$ (III) AF & \multicolumn{2}{|c|}{ (II) AS \& (III) AF } \\
\hline \multicolumn{2}{|c|}{$<0.001^{\star}$} & $<0.001^{*}$ & \multicolumn{2}{|c|}{0.135} \\
\hline
\end{tabular}

AR: Arabs. AS: Asians. AF: Africans. I: Group I, II: Group II. III: Group III.

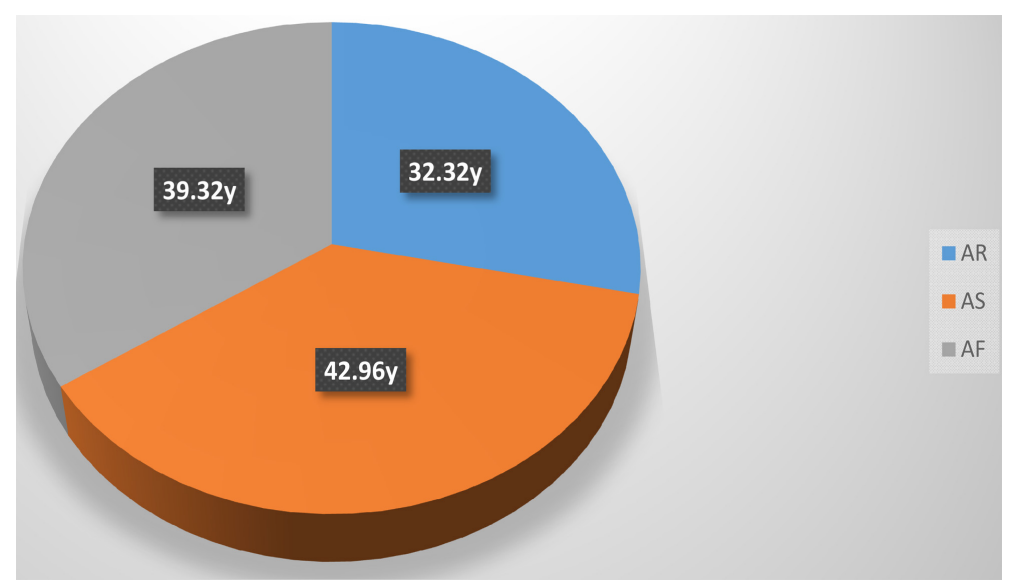

Figure 1. The mean of age of the study groups. AR: Arabs. AS: Asians. AF: Africans. 
(NCs/D), there was an increase in the mean of $\mathrm{NCs} / \mathrm{D}$ more than ten cigarettes per day (>10 Cs/D) without statistical significance differences in group I, II \& III $(14.13 \pm 6.9),(12.13 \pm 4.3)$ and $(11.9 \pm 5.5)$. Moreover, of the 300 participants, 271 (90.3\%) had HbAlc <7\% and 29 (9.7\%) had HbAlc > 7\%. Consequently, the number of patients in the current study with $\mathrm{HbAlc}<7 \%$ is more than HbAlc $>7 \%$ in group I, II \& III without statistical significance differences $(p>$ $0.05)$ (Table $2 \&$ Figure 2).

Tables 3-5 and Figures 3-5 show the gingival and oral hygiene status, Periodontal parameters of periodontitis (severity) staging, and complexity of participants within racial/ethnic groups (group I, II, and III) in the current study.

Table 2. Characteristics of participants.

\begin{tabular}{|c|c|c|c|c|c|c|c|c|c|}
\hline & & \multicolumn{6}{|c|}{ Groups } & \multicolumn{2}{|c|}{ Chi-square } \\
\hline & & \multicolumn{2}{|c|}{$\mathrm{AR}$} & \multicolumn{2}{|c|}{ AS } & \multicolumn{2}{|c|}{$\mathrm{AF}$} & $\mathrm{X}^{2}$ & P-value \\
\hline \multirow{2}{*}{ Age } & Range & \multicolumn{2}{|c|}{$14-89$} & \multicolumn{2}{|c|}{$21-76$} & \multicolumn{2}{|c|}{$18-81$} & \multirow{2}{*}{16.253} & \multirow{2}{*}{$<0.001^{*}$} \\
\hline & Mean \pm SD & \multicolumn{2}{|c|}{$32.32 \pm 14.54$} & \multicolumn{2}{|c|}{$42.96 \pm 12.70$} & \multicolumn{2}{|c|}{$39.32 \pm 12.92$} & & \\
\hline \multirow{2}{*}{ Gender } & Female & 34 & $34.0 \%$ & 33 & $33.0 \%$ & 33 & $33.0 \%$ & \multirow{2}{*}{0.030} & \multirow{2}{*}{0.985} \\
\hline & Male & 66 & $66.0 \%$ & 67 & $67.0 \%$ & 67 & $67.0 \%$ & & \\
\hline \multirow{2}{*}{ Smoking } & $<10 \mathrm{Cs} / \mathrm{D}$ & 70 & $70.0 \%$ & 69 & $69.0 \%$ & 72 & $72.0 \%$ & \multirow[b]{2}{*}{0.224} & \multirow[b]{2}{*}{0.894} \\
\hline & $>10 \mathrm{Cs} / \mathrm{D}$ & 30 & $30.0 \%$ & 31 & $31.0 \%$ & 28 & $28.0 \%$ & & \\
\hline \multirow{2}{*}{ Diabetic } & $\mathrm{HbAlc}>7 \%$ & 5 & $5.0 \%$ & 11 & $11.0 \%$ & 13 & $13.0 \%$ & \multirow{2}{*}{4.334} & \multirow{2}{*}{0.114} \\
\hline & $\mathrm{HbA} 1 \mathrm{c}<7 \%$ & 95 & $95.0 \%$ & 89 & $89.0 \%$ & 87 & $87.0 \%$ & & \\
\hline
\end{tabular}

\pm SD: Standard deviation. Cs/D: Cigarettes/day. HbAc1: Glycosylated hemoglobin.

Table 3. Gingival and oral hygiene status of participants.

\begin{tabular}{|c|c|c|c|c|c|c|c|c|c|}
\hline & & \multicolumn{6}{|c|}{ Groups } & \multicolumn{2}{|c|}{ Chi-square } \\
\hline & & \multicolumn{2}{|c|}{ Group I (AR) } & \multicolumn{2}{|c|}{ Group II (AS) } & \multicolumn{2}{|c|}{ Group III (AF) } & \multirow{2}{*}{$\mathrm{X}^{2}$} & \multirow{2}{*}{ P-value } \\
\hline & & $\mathbf{N}$ & $\%$ & $\mathbf{N}$ & $\%$ & $\mathbf{N}$ & $\%$ & & \\
\hline & $<10$ & 14 & $14.0 \%$ & 11 & $11.0 \%$ & 11 & $11.0 \%$ & & \\
\hline \multirow[t]{2}{*}{ GBI } & $10-30$. & 29 & $29.0 \%$ & 32 & $32.0 \%$ & 29 & $29.0 \%$ & 0.788 & 0.940 \\
\hline & $>30$ & 57 & $57.0 \%$ & 57 & $57.0 \%$ & 60 & $60.0 \%$ & & \\
\hline \multicolumn{10}{|c|}{ ANOVA test } \\
\hline \multirow[t]{5}{*}{ PCR \% } & \multicolumn{2}{|r|}{ Mean \pm SD } & \multicolumn{2}{|r|}{ Mean \pm SD } & & \multicolumn{2}{|l|}{ Mean \pm SD } & $\mathrm{F}$ & P-value \\
\hline & \multicolumn{2}{|r|}{$54.83 \pm 27.01$} & & $59.88 \pm 22.51$ & & \multicolumn{2}{|l|}{$51.77 \pm 27.12$} & 2.554 & 0.079 \\
\hline & \multicolumn{9}{|c|}{ Tukey's test } \\
\hline & \multicolumn{5}{|c|}{ I\&II } & \multicolumn{2}{|l|}{ I\&III } & \multicolumn{2}{|c|}{ II\&III } \\
\hline & \multicolumn{5}{|c|}{0.346} & \multicolumn{2}{|l|}{0.675} & \multicolumn{2}{|c|}{0.067} \\
\hline
\end{tabular}

GBI: Gingival bleeding index. N: Number. PCR: Plaque control record. 
Table 4. Periodontal parameters of periodontitis (severity) staging.

\begin{tabular}{|c|c|c|c|c|c|c|c|}
\hline & & \multirow[b]{2}{*}{ Mean \pm SD } & \multicolumn{2}{|c|}{ ANOVA } & \multicolumn{3}{|c|}{ Tukey's test } \\
\hline & & & F & P-value & I \& II & I \& III & II \& III \\
\hline \multirow{3}{*}{ CAL } & $\mathrm{AR}$ & $4.760 \pm 1.980$ & \multirow{3}{*}{6.798} & \multirow{3}{*}{$<0.001^{*}$} & \multirow{3}{*}{$0.002^{*}$} & \multirow{3}{*}{$0.013^{\star}$} & \multirow{3}{*}{0.817} \\
\hline & AS & $5.785 \pm 2.029$ & & & & & \\
\hline & $\mathrm{AF}$ & $5.605 \pm 2.276$ & & & & & \\
\hline \multirow{3}{*}{ RBL } & $\mathrm{AR}$ & $20.117 \pm 10.880$ & \multirow{3}{*}{6.911} & \multirow{3}{*}{$<0.001^{\star}$} & \multirow{3}{*}{$0.001^{*}$} & \multirow{3}{*}{0.258} & \multirow{3}{*}{0.086} \\
\hline & AS & $26.850 \pm 14.350$ & & & & & \\
\hline & $\mathrm{AF}$ & $22.979 \pm 13.091$ & & & & & \\
\hline \multirow{3}{*}{ NMTP } & $\mathrm{AR}$ & $0.210 \pm 0.701$ & \multirow{3}{*}{4.461} & \multirow{3}{*}{$0.012^{*}$} & \multirow{3}{*}{$0.011^{*}$} & \multirow{3}{*}{0.094} & \multirow{3}{*}{0.701} \\
\hline & AS & $0.750 \pm 1.546$ & & & & & \\
\hline & $\mathrm{AF}$ & $0.600 \pm 1.531$ & & & & & \\
\hline
\end{tabular}

CAL: Clinical attachment loss. RBL: Radiographic bone loss. NMTP: Number of teeth missing due periodontal diseases.

Table 5. Periodontal parameters of periodontitis staging (complexity).

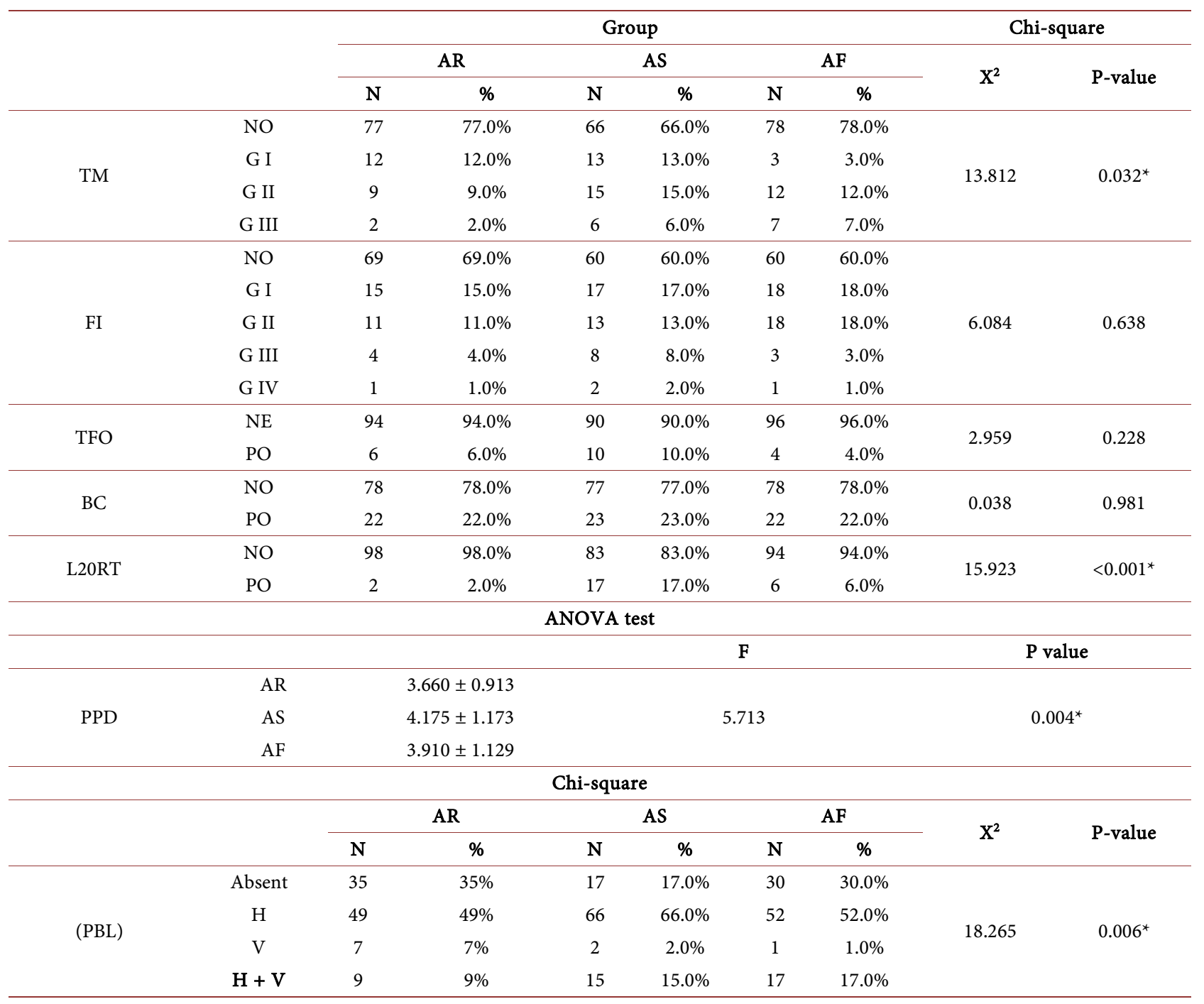

TM: Tooth mobility. FI: Grade of function involvement. TFO: Secondary trauma from occlusion. BC: Bite collapse. L20RT: Less than 20 remaining teeth. PPD: Periodontal pocket depth. PBL: Pattern of bone loss. NO: No present, G: Grade. NE: Negative, PO: Positive. H: Horizontal. V: Vertical. 


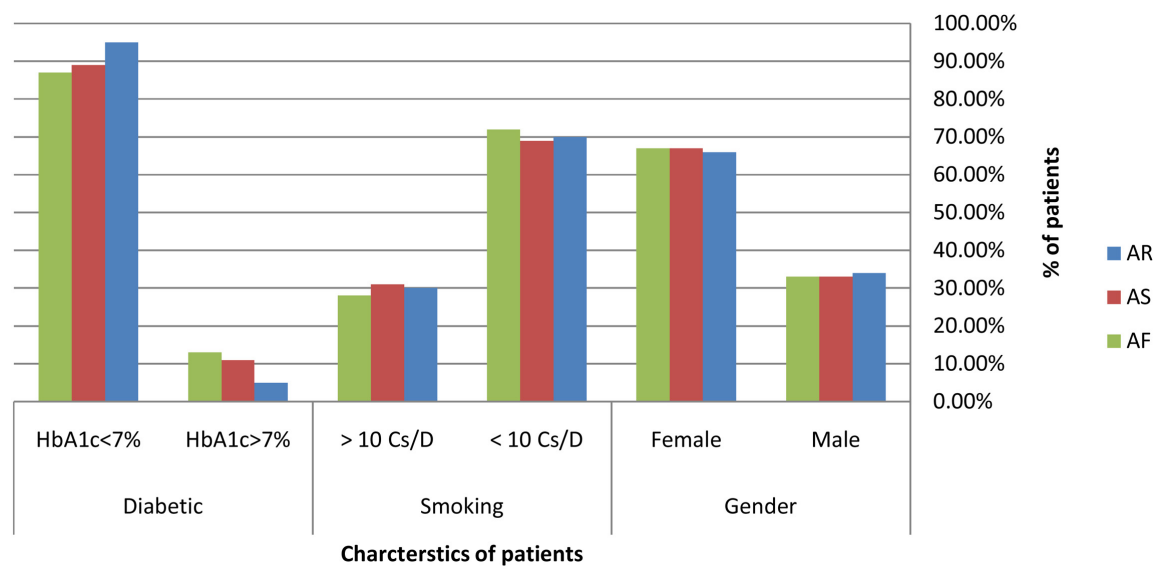

Figure 2. Characterstics of participants. Cs/D: Cigarettes/day. HbAc1: Glycosylated hemoglobin. AR: Arabs. AS: Asians. AF: Africans.

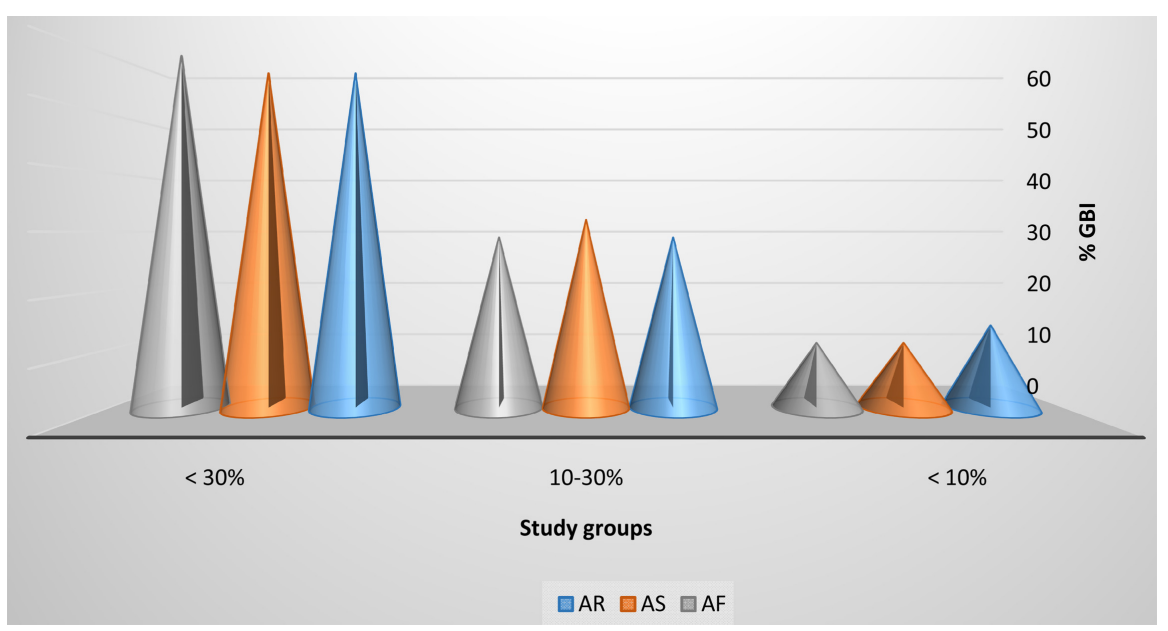

(a)

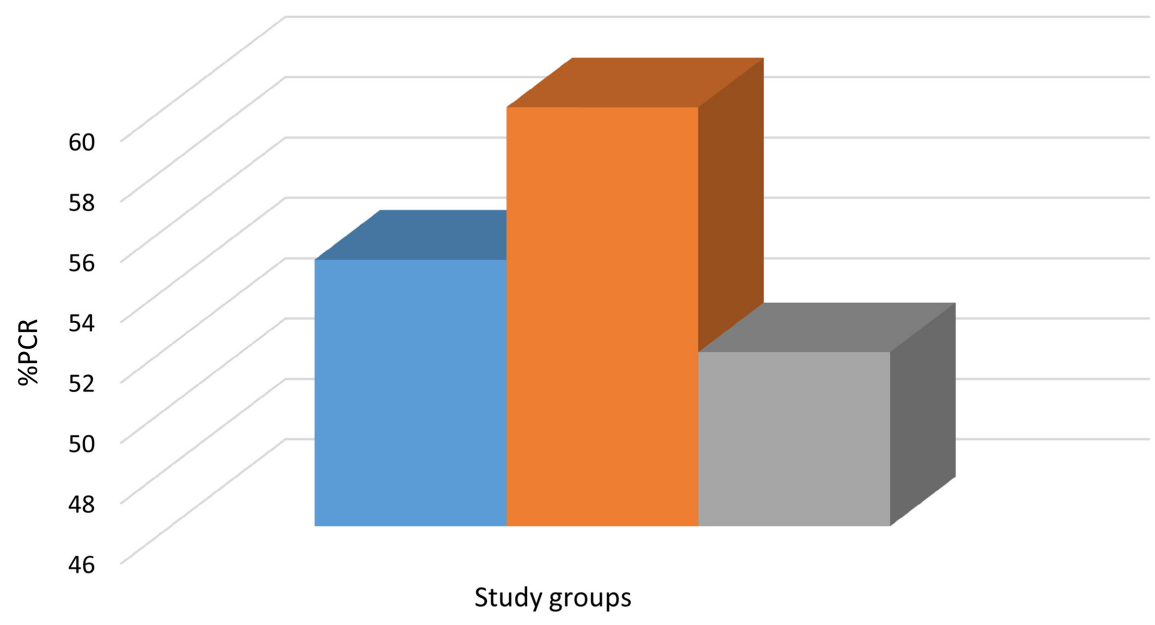

$\because \mathrm{AR} \backsim \mathrm{AS} \backsim \mathrm{AF}$

(b)

Figure 3. (a): Gingival bleeding index. \% GBI: Percentage of gingival bleeding index. AR: Arabs. AS: Asians. AF: Africans. (b) The percentage of plaque control record. \% PCR: Percentage of plaque control. AR: Arabs. AS: Asians. AF: Africans. 


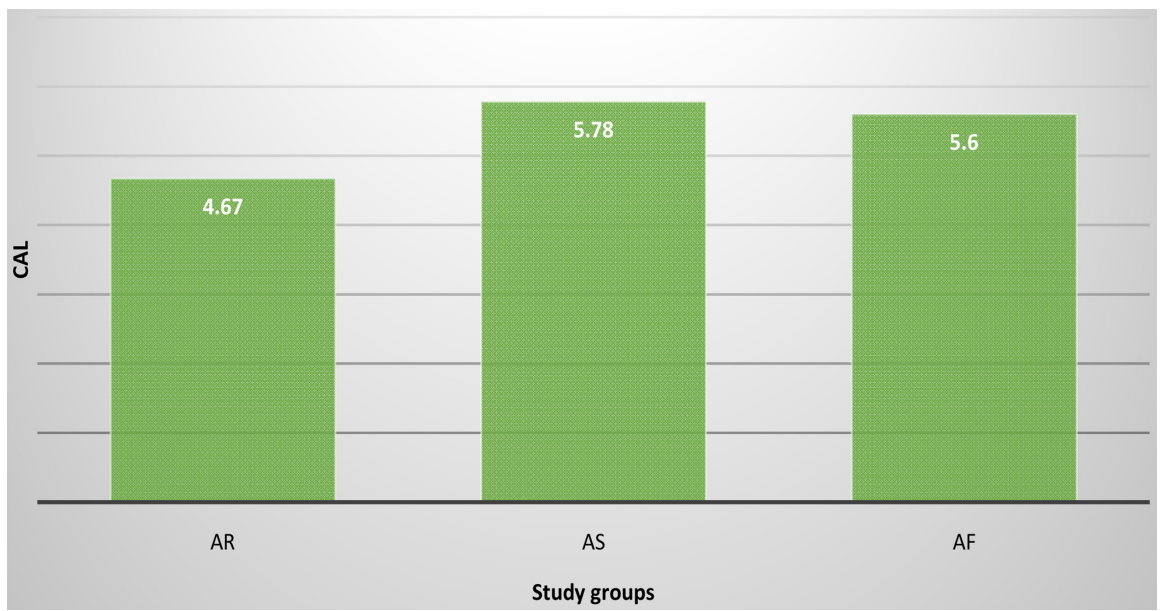

(a)

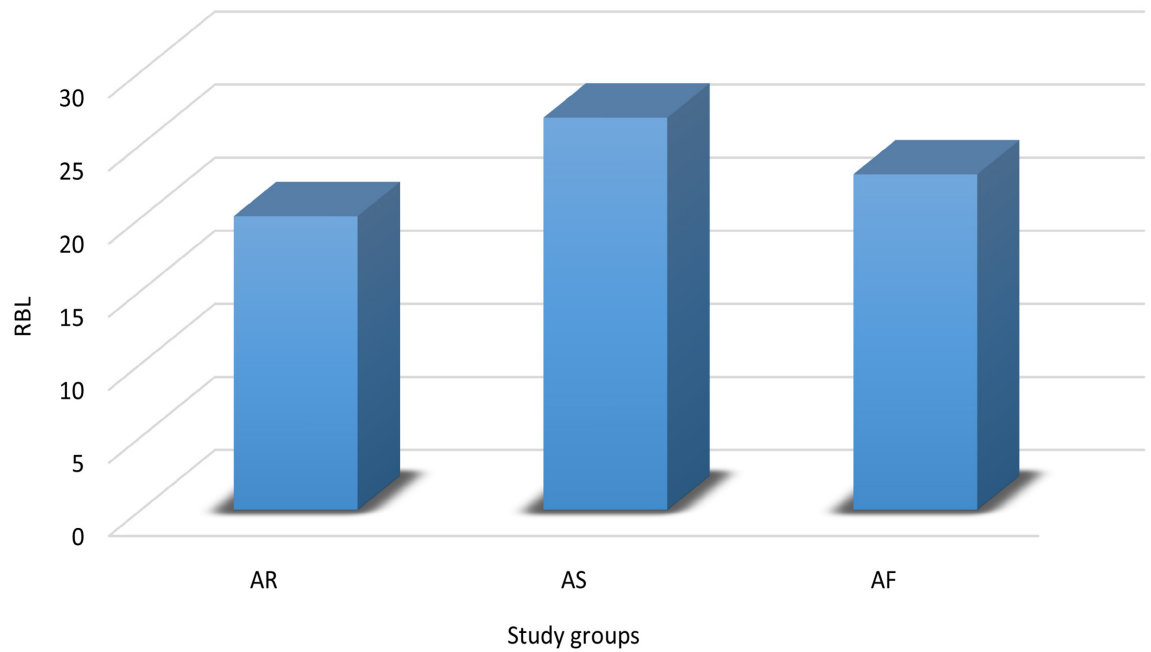

(b)

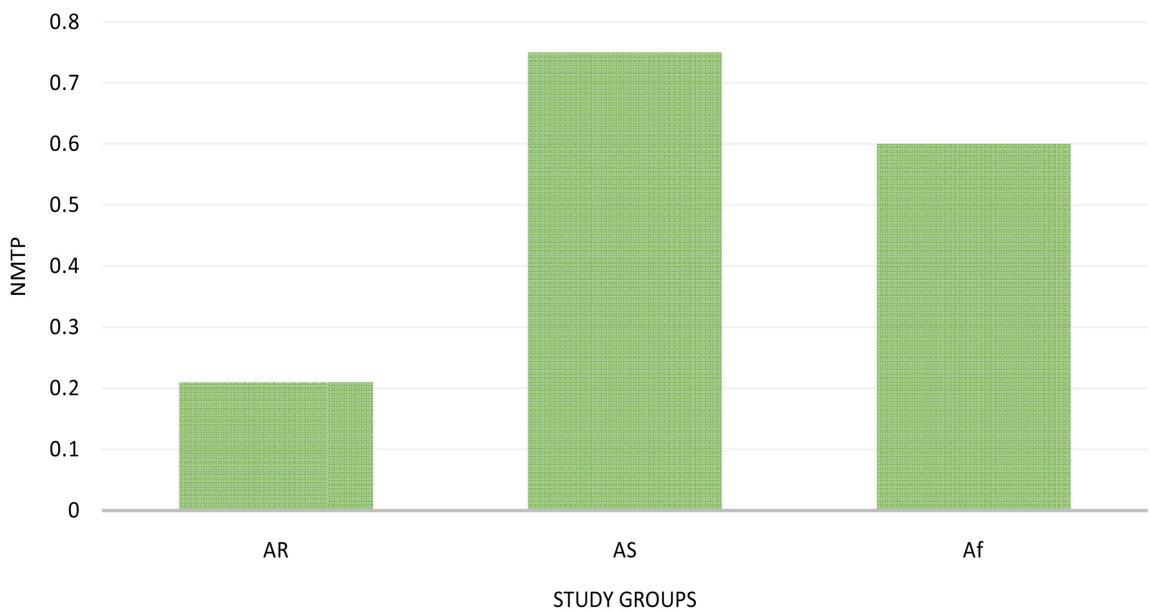

(c)

Figure 4. (a): Clinical parameters of periodontitis staging (CAL). CAL: Clinical attachment loss. AR: Arabs. AS: Asians, AF: Africans. (b) Clinical parameters of periodontitis staging (RBL). RBL: Radiographic bone loss, AR; Arabs, AS: Asians, AF: Africans. (c) Clinical parameters of periodontitis staging (NMTP). NMTP: Number of missing teeth due to periodontitis. AR: Arabs. AS: Asians, AF: Africans. 


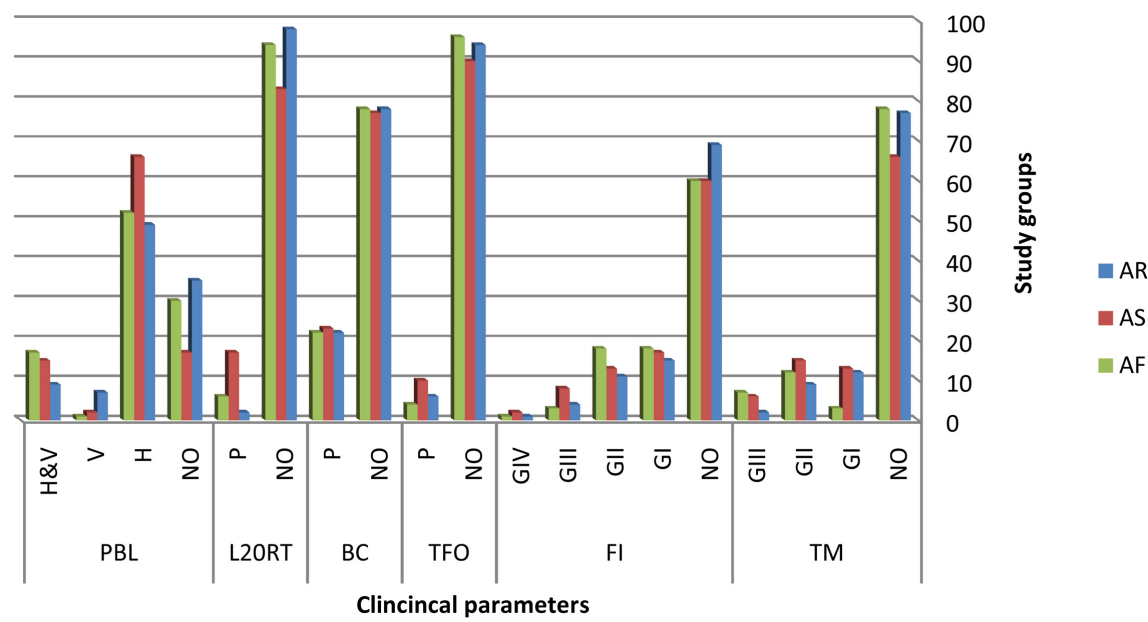

Figure 5. Clinical parameters of periodontitis staging complexity. TM: Tooth mobility. FI: Grade of function involvement. TFO: Secondary trauma from occlusion. BC: Bite collapse. L20RT: Less than 20 remaining teeth. PPD: Periodontal pocket depth. PBL: Pattern of bone loss. NO: No present, G: Grade. NE: Negative, PO: Positive. H: Horizontal. V: Vertical.

There was an increase in PCR, GBI, CAL, RBL, NMTP, and PPD among the patients of Asians more than group Arabs and Africans without statistical significance differences of PCR and GBI in the comparison between these three groups according to ANOVA test, Tukey's test, and Chi-square test. There were highly statistically significant differences between these groups according to the ANOVA test in CLA, RBL, NMTP, and PPD. On the other hand, there were differences in periodontal parameters of periodontitis severity without statistical significance differences according to Tukey's test except between Arabs and Africans in CAL, where there were statistical significance differences $(p=0.013)$.

There was no TM, FI, TFO, BC, and L 20 RT detected among most of the patients of groups, and there was a statistically significant difference in TM and highly statistically significant difference in L20 RT without statistically significant differences in FI, TFO, and BC in the comparison between Arabs, Asians, and Africans. Regarding the pattern of bone loss, horizontal bone loss was more than vertical, and both horizontal \& vertical with highly statistically significant differences $(p=0.006)$. It was in Africans more than Arabs and Asians. Moreover, the Vertical bone loss of Arabs was more than Asians and Africans, while both horizontal and vertical bone loss of Africans was more than Arabs and Asians. There was a correlation between the plaque control record (O'Leary index) and the clinical parameters of periodontitis severity and progression except for furcation involvement (Table 6).

Table 7 and Figure 6 show gingivitis extent, severity, and grading where the localized gingivitis among the participants of groups I, II, and III was $43 \%, 43 \%$, and $40 \%$, and the generalized gingivitis was $57 \%, 57 \%$, and $60 \%$ respectively. There were no significant differences in the extent of gingivitis between Arabs and Asians, but it was more among Africans compared to Arabs and Asians. 
Table 6. Correlation between PCR, age, and periodontitis staging and grading.

\begin{tabular}{cccc}
\hline \multirow{2}{*}{ Correlations } & & \multicolumn{2}{c}{ PCR } \\
\cline { 3 - 4 } & & $\mathrm{r}$ & P-value \\
\hline \multicolumn{1}{c}{ Age } & & 0.134 & $0.02^{*}$ \\
\hline $\begin{array}{c}\text { Periodontitis } \\
\text { (severity) staging }\end{array}$ & CAL & 0.330 & $<0.001^{*}$ \\
& NML & 0.221 & $<0.001^{*}$ \\
Periodontitis & PPD & 0.180 & $0.002^{*}$ \\
Staging complexity & TM & 0.313 & $<0.001^{*}$ \\
& FI & 0.233 & $<0.001^{*}$ \\
Periodontitis & No. Cs/D & 0.104 & 0.073 \\
Progression (grading) & $\%$ HbAlc & 0.321 & $0.002^{*}$ \\
\hline
\end{tabular}

CAL: Clinical Attachment loss. RBL: Radiographic bone loss, NMTP: Number of missing teeth due to periodontitits, PPD: Periodontal pocket depth. TM: Tooth mobility. FI: Furcation involvement. No. Cs/D: Number of cigarettes per day. \% HbAlc: Percentage of Glycosylated hemoglobin.

Table 7. Gingivitis extent, severity and grading.

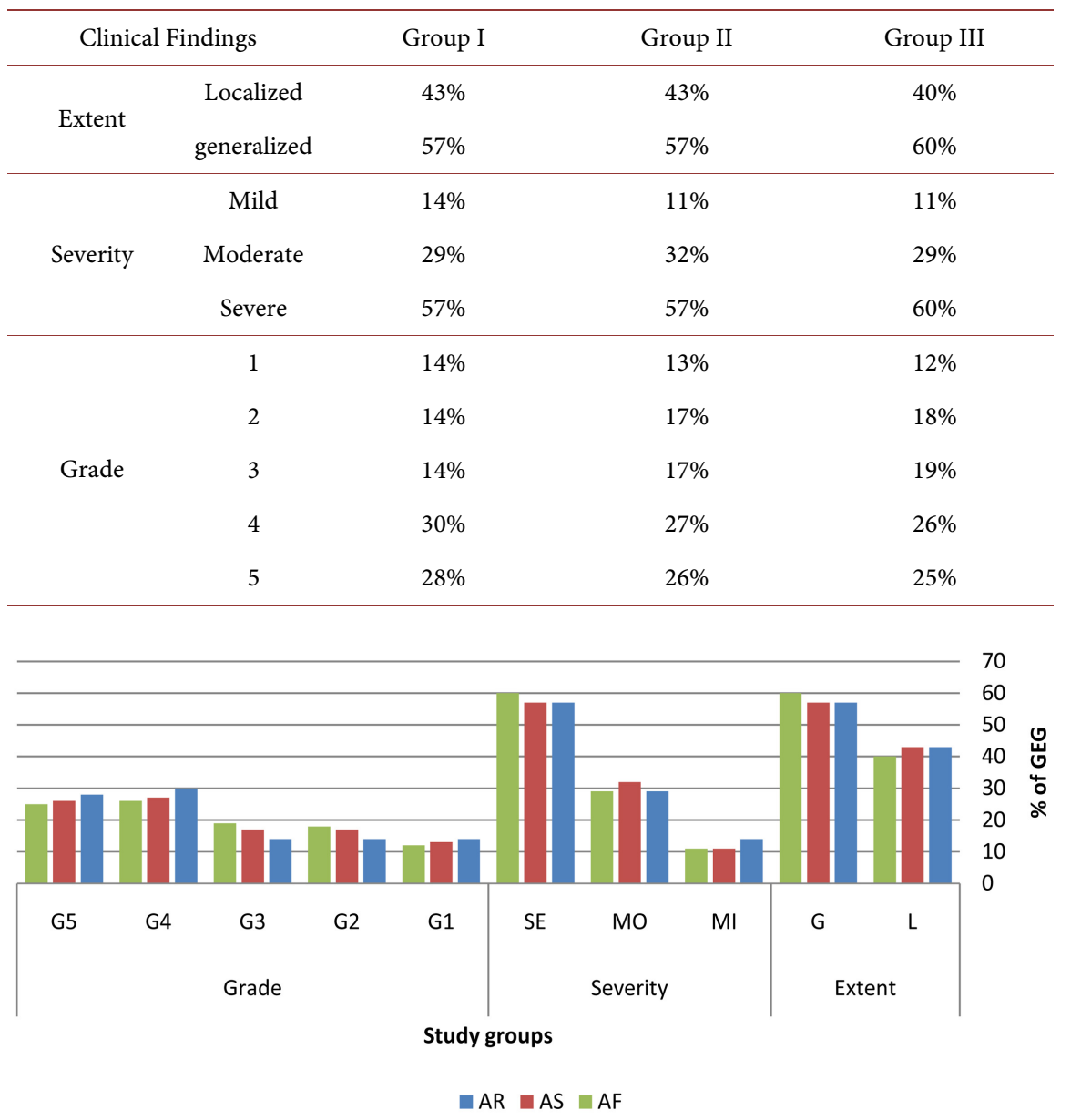

Figure 6. Gingivitis extent, severity and grading. L: Localized. G: Generalized. MI: Mild. MO: Moderate. SE: Severe. G1: Grade 1. G2: Grade 2. G3: Grade 3. G4: Grade 4. G5: Grade 5. 
Mild gingivitis among Arabs was more, while moderate and severe gingivitis among Asians was more. More, detailed grading of gingivitis is also in Table 7 and Figure 7. Grade 1, 4, and 5 gingivitis of Arabs more than Asians and Africans, and Grade 2 and 3 gingivitis of Africans more than Arabs and Asians.

Table 8 and Figure 7 exhibit the clinical parameters of periodontitis extent and severity within each group. In all groups, generalized periodontitis was higher than localized periodontitis. Arabs displayed the highest periodontitis severity where $18 \%$ of them reached stage IV of periodontitis (very severe), followed by African and Asian 17\% and 16\% reached stage IV periodontitis. The progression of periodontitis rate of the participants in the current study increased for all groups. Table 9 and Figure 8 displayed that the majority (64\%, $61 \% \& 68 \%$ ) of Arabs, Asians, and Africans had a moderate rate of periodontitis, while $17 \%, 21 \%$, and $20 \%$ of them had a rapid rate of periodontitis compared to $19 \%, 18 \%$, and $12 \%$ had a slow rate of periodontitis.

\section{Discussion}

Periodontitis comprises one of the global problems in the oral cavity [1]. The main objective of the evaluation studies for severity and progression of periodontitis is to supply the dental practitioners and periodontists with significant data to help them in the diagnosis and the assessment of prognostic factors with

Table 8. Periodontitis extent and severity (stages).

\begin{tabular}{cccccccc}
\hline \multirow{2}{*}{ Groups } & \multicolumn{2}{c}{ Extent } & \multicolumn{3}{c}{$\begin{array}{c}\text { Severity } \\
\text { (CAL, RBL, NMTP, PPD, FI) }\end{array}$} & $\begin{array}{c}\text { Complexity (IV) } \\
\text { (TM, TFO, BC, <20 RT) }\end{array}$ \\
\cline { 2 - 6 } AR & L & G & I & II & III & IV & $18 \%$ \\
AS & $86 \%$ & $14 \%$ & $33 \%$ & $13 \%$ & $36 \%$ & $00 \%$ & $13 \%$ \\
AF & $86 \%$ & $14 \%$ & $35 \%$ & $10 \%$ & $38 \%$ & $3 \%$ & $14 \%$ \\
\hline
\end{tabular}

AR: Arabs. AS: Asians. AF: Africans. L: Localized. G: Generalized. I: Stage I. II: stage II, III: Stage III and IV: Stage IV. CAL: Clinical Attachment loss. RBL: Radiographic bone loss, NMTP: Number of missing teeth due to periodontitis, PPD: Periodontal pocket depth, TM: Tooth mobility. FI: Furcation involvement. TFO: Secondary trauma from occlusion, BC: Bite collapse, $<20 \mathrm{RT}:<20$ remaining teeth.

Table 9. Periodontitis progression (grading).

\begin{tabular}{|c|c|c|c|c|}
\hline & & $\begin{array}{c}\text { A } \\
\text { (\% bone loss/age } \\
<0.25) \text { and } \\
\text { (Non-smokers and } \\
\text { non-diabetic) }\end{array}$ & $\begin{array}{c}\text { B } \\
\text { (\% bone loss/age } \\
0.25 \text { to } 1.0) \text { and } \\
(<10 \mathrm{Cs} / \mathrm{D} \text { or } \\
\text { HbAlc }<7.0 \%)\end{array}$ & $\begin{array}{c}\text { C } \\
(\% \text { bone } \\
\text { loss/age }>1.0) \text { and } \\
(>10 \mathrm{Cs} / \mathrm{D} \text { or } \\
\text { HbAlc } \geq 7.0 \%)\end{array}$ \\
\hline \multirow{3}{*}{$\begin{array}{c}\text { Grade } \\
\text { modifiers }\end{array}$} & AR & $19 \%$ & $64 \%$ & $17 \%$ \\
\hline & AS & $18 \%$ & $61 \%$ & $21 \%$ \\
\hline & $\mathrm{AF}$ & $12 \%$ & $68 \%$ & $20 \%$ \\
\hline
\end{tabular}

A: Grade A. B: Grade B. C: Grade C. AR: Arabs. AS Asians. AF: Africans. No. Cs/D: Number of cigarettes per day. \% HbA1c: Percentage of Glycosylated hemoglobin. 


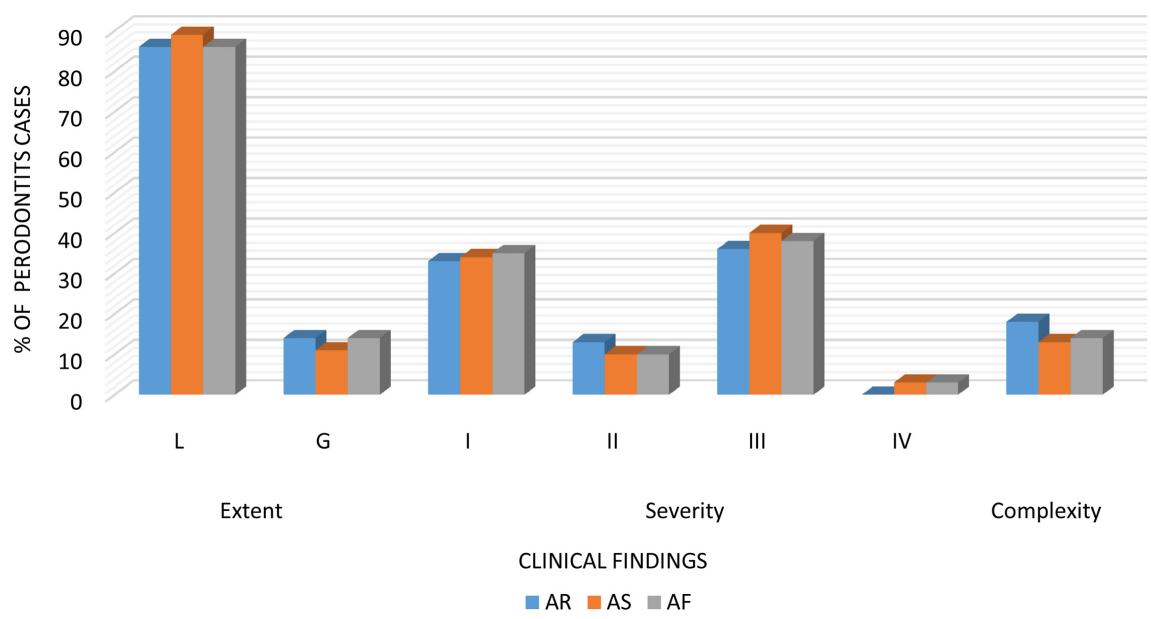

Figure 7. Periodontitis extent and severity (staging). L: Localized, G: Generalized. I: Stage I. II: stage II, III: Stage III and IV: Stage IV. AR: Arabs. AS: Asians. AF: Africans.

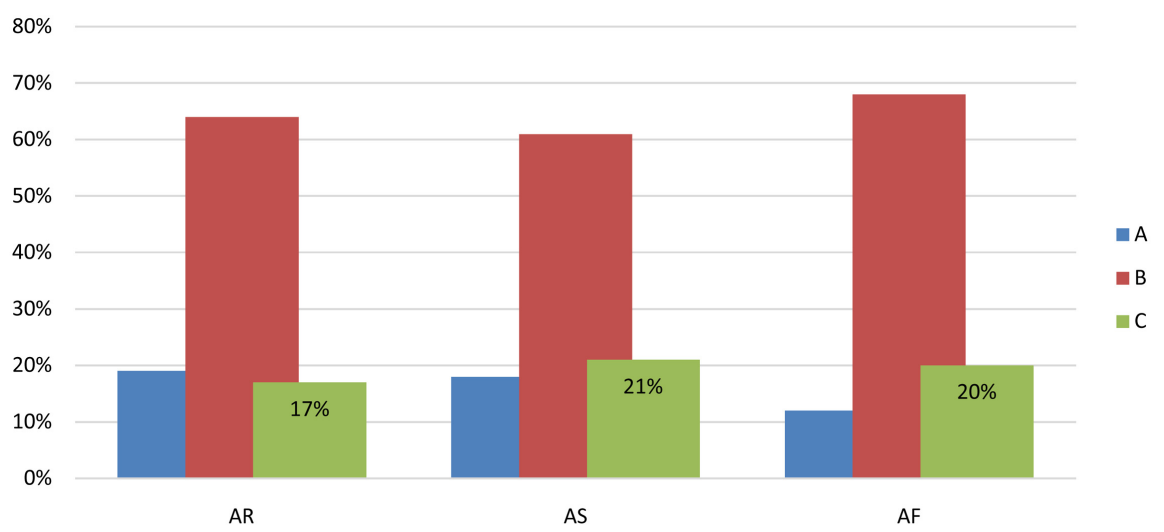

Figure 8. Periodontitis progression (grading). A: Grade A. B: Grade B. C: Grade C. AR: Arabs. AS: Asians. AF: Africans.

planning periodontal therapy. These data comprise the presence of plaque, gingival bleeding, clinical attachment loss, radiographic bone loss, and periodontal pocket formation [32]. Moreover, age, smoking, and other factors associated with socioeconomic status like expatriation [33] [34] [35].

Based on our information, the present study is the first study conducted on selected expatriate population-based samples living in the same area and the same environmental conditions to assess the severity and progression of periodontitis among multi-ethnic patients in Aseer region, Saudi Arabia. This study detected differences in severity and progression of periodontitis among the three ethnic groups, and there were correlations between oral hygiene status and age. Moreover severity, and progression of periodontitis. These findings consistent with many previous studies that have exhibited periodontitis more severe in some ethnic groups [36] [37], and other studies displayed that progression of periodontitis was varying among ethnic groups [35] [38].

The results displayed that $57 \%$ of Arabs, $57 \%$ of Asians, and $60 \%$ of Africans had gingival bleeding more than $30 \%$ and that means generalized severe gingivi- 
tis in 2017 classification compared to $43 \%$ of Arabs, 43\% of Asians, and $60 \%$ of Africans had localized mild and moderate gingivitis that means gingival bleeding was less than $30 \%$. Regarding grading of gingivitis grade 4 , it is more than other grades, but the grading of gingivitis among Arabs is more than Asians and Africans. The present study revealed that most of the participants were suffering from gingivitis with periodontitis. This finding is similar to the study results of Idrees, et al. [39]. Moreover, Zhang, et al. detected that gingival inflammation affected $97.9 \%$ of Chinese adults and $95.7 \%$ of American adults [40]. It is well known that there is a closed association between dental plaque and gingivitis, and this demonstrates the association in this study between plaque formation and gingivitis among all participants [41].

In 2017, periodontitis was assessed based on the attachment loss in the interdental area (CAL) at $\geq 2 \mathrm{~mm}$ or as buccal CAL $\geq 3 \mathrm{~mm}$ with $>3 \mathrm{~mm}$ pocket formation on $\geq 2 \mathrm{~mm}$ teeth [42].

The main objective of the clinical examination was to clarify whether the occurrence and measure of attachment loss varied among the three ethnic groups. The attachment loss was significantly different among the three ethnic groups, but there was an increase in attachment loss in Asians more than Arabs and Africans. The clinical periodontal parameters reflected the severity of periodontitis among the participants in the current study.

In periodontics, radiographic examination supplements the clinical examination, helping to diagnose periodontitis [43]. Several previous studies revealed that the prevalence of horizontal bone loss more than vertical bone loss among the patients of periodontitis. These findings are similar to those found by this study which appeared that the horizontal bone loss among Arabs, Asians, and Africans participants more than vertical bone loss [44] [45] [46].

There was an association between an increase in age and clinical attachment loss. These findings are comparable with Neely et al., who clarified a positive correlation between age and clinical attachment loss [33].

When compared with the previous Libyan study, there were a high percentage of participants who had shallow pockets and deep pockets whereas this study exhibited that most Arabs participants had shallow pockets [47].

In the present study, there was an association between an increased $\mathrm{HbAlc}$ level of more than $7 \%$ and Clinical attachment loss, the gingival bleeding index where the African participants had HbAlc level of more than 7\% moreover clinical attachment loss, gingival bleeding index more than Arabs and Asians participants. These results are consistent with previous studies that revealed that there was a positive correlation between an increase of HbAlc level and clinical attachment loss, gingival bleeding index [48] [49]. Surprisingly, Africans had a higher value of glycosylated hemoglobin than Arabs and Asians, with fewer smokers than the overall study participation. These results indicate that the destruction of periodontal tissues more among Africans than Arabs and Asians, Consequently Africans may have other risk factors linked to this racial/ethnic 
group, which need more study.

The current study assessed the association of the presence grade of tooth mobility and other results such as radiographic bone loss, tooth loss due to periodontitis, furcation involvement, secondary occlusal trauma, bite collapse and less than 20 remaining teeth with a specific ethnic group where these periodontal parameters were more among Asians participants more than Arabs and Africans participants. These findings are consistent with an increased plaque control record percentage among Asian participants more than Arabs and African participants. In another previous study, there was a correlation between the degree of tooth mobility, the amount of radiographic alveolar bone loss, and periodontal pocket depth. Similarly, there was an increase in tooth mobility, the amount of radiographic alveolar bone loss, and periodontal pocket depth among Asian participants more than Arabs and African participants [50] [51].

Moreover, there was an increase in these clinical parameters among consumers of $\geq 10$ cigarettes/day (Asian participants) more than other ethnic groups in this study. These results agree with the results of earlier studies that exhibited an increase in tooth mobility and severity of periodontal destruction among smokers more than non-smokers [52] [53].

On the other hand, there was no association between the type of radiographic alveolar bone loss (horizontal or angular). and other clinical parameters of periodontal destruction among the ethnic groups of the current study, where the horizontal bone loss was more among Asian participants whereas the angular was more among Arabs, few studies have examined the relationship between the type of radiographic alveolar bone loss and progression of periodontitis [54].

Borrell et al. detected that African-Americans had periodontitis more severity than other populations in the United States [55]. Consistent with the clinical findings of the current study detected that African participants had higher severity and progression periodontitis than Arabs and Asians. The results of this study exhibited that most Africans and Arabs participants had generalized periodontitis stage III and IV, grade B more than Asians, whereas most Arabs and Asians had localized periodontitis stage I and II, grade A among most Arabs and grade $\mathrm{C}$ among most of Asians more than Africans due to most of Asians were heavy cigarette smokers (more than 10cigarettes per day). Furthermore, there was an association between the increase of the progression of periodontitis and an increase of cigarettes smoked per day among the subjects in the current study where the mean age of Asian participants who were with grade $(C)$ periodontitis more than the mean age of Arabs and Africans participants who were with grade (A) and (B) of periodontitis respectively. These clinical findings were in agreement with former studies, which indicated an increase in periodontitis with an increase in age [56] [57]. These clinical findings also corresponding with other clinical and epidemiological studies that exhibited that periodontal disease increases with the greater the number of cigarettes smoked a day [58].

In other previous studies on different ethnic groups, Africans had a higher 
severity and progression of periodontitis than other groups [59]. Similarly, in this study, the severity of periodontitis among Africans and Asians is more than Arabs but the complexity of periodontitis severity among Arabs is more than Asians and Africans.

\section{Strength and Limitations}

The strength and limitation of the present study depend on the racial/ethnic variations of its participants. Moreover, there is very little knowledge about the severity of periodontal diseases of expatriates in Saudi Arabia, compares to each other in this country. This study did not collect any information from participants about the education level, socioeconomic status, oral hygiene measures, and the dental clinics' visit frequency. As there are different origins of expatriates in Saudi Arabia, it is essential that we fully understand the risk factors of periodontal disease among the racial/ethnic groups of the current study to help them and reduce the severity and progression of periodontitis. Additional studies with larger sample sizes are necessary to explain the impact of racial differences on oral health and periodontal disease extent, staging and grading.

\section{Conclusion}

In conclusion, the present study has reported changes in the severity and progression of periodontal diseases among the three ethnic groups, but the variables that may be associated with ethnicity did not examine such as, education level, economic level, and occupational status. Therefore, the results of this study suggest that these variables may affect the severity and progression of periodontal diseases.

\section{Acknowledgements}

The authors would like to thank the colleagues in the college of dentistry, King Khalid University, who provided help during the collection of this study data.

\section{Conflicts of Interest}

The authors declare no conflicts of interest regarding the publication of this paper.

\section{References}

[1] Petersen, P.E., Bourgeois, D., Ogawa, H., Estupinan-Day, S. and Ndiaye, N. (2005) The Global Burden of Oral Diseases and Risks to Oral Health. Bulletin of the World Health Organization, 83, 661-669.

[2] Mawardi, H.H., Elbadawi, L.S. and Sonis, S.T. (2015) Current Understanding of the Relationship between Periodontal and Systemic Diseases. Saudi Medical Journal, 36, 150-158. https://doi.org/10.15537/smj.2015.2.9424

[3] Petersen, P.E. and Ogawa, H. (2012) The Global Burden of Periodontal Disease: Towards Integration with Chronic Disease Prevention and Control. Periodontology, 60, 15-39. https://doi.org/10.1111/j.1600-0757.2011.00425.x 
[4] Eke, P.I., Dye, B.A., Wei, L., Slade, G.D., Thornton-Evans, G.O., Borgnakke, W.S., et al. (2015) Update on Prevalence of Periodontitis in Adults in the United States: NHANES 2009 to2012. Journal of Periodontology, 86, 611-622. https://doi.org/10.1902/jop.2015.140520

[5] Eke, P.I., Wei, L., Borgnakke, W.S., Thornton-Evans, G., Zhang, X., Lu, H., et al. (2016) Periodontitis Prevalence in Adults $>/=65$ Years of Age, in the USA. Periodontology 2000, 72, 76-95. https://doi.org/10.1111/prd.12145

[6] Meyle, J. and Chapple, I. (2015) Molecular Aspects of the Pathogenesis of Periodontitis. Periodontology 2000, 69, 7-17. https://doi.org/10.1111/prd.12104

[7] Albandar, J.M., Brunelle, J.A. and Kingman, A. (1999) Destructive Periodontal Disease in Adults 30 Ears of Age and Older in the United States, 1988-1994. Journal of Periodontology, 70, 13-29. https://doi.org/10.1902/jop.1999.70.1.13

[8] Sheiham, A. and Netuveli, G.S. (2002) Periodontal Diseases in Europe. Periodontology 2000, 29, 104-121. https://doi.org/10.1034/j.1600-0757.2002.290106.x

[9] Corbet, E.F., Zee, K.Y. and Lo, E.C. (2002) Periodontal Diseases in Asia and Oceania. Periodontology 2000, 29, 122-152.

https://doi.org/10.1034/j.1600-0757.2002.290107.x

[10] Natto, Z.S. and Al-Zahrani, M.S. (2010) Periodontal Bone Loss and Self-Reported Medical Conditions in a Dental School Patient Population. Journal of the International Academy of Periodontology, 12, 104-109.

[11] Hybels, C.F., Wu, B., Landerman, L.R., Liang, J., Bennett, J.M. and Plassman, B.L. (2016) Trends in Decayed Teeth among Middle-Aged and Older Adults in the United States: Socioeconomic Disparities Persist over Time. Journal of Public Health Dentistry, 76, 287-294. https://doi.org/10.1111/jphd.12153

[12] Eke, P.I., Dye, B.A., Wei, L., Thornton-Evans, G.O. and Genco, R.J. (2012) Prevalence of Periodontitis in Adults in the United States: 2009 and 2010. Journal of Dental Research, 91, 914-920. https://doi.org/10.1177/0022034512457373

[13] Elani, H.W., Harper, S., Allison, P.J., Bedos, C. and Kaufman, J.S. (2012) Socio-Economic Inequalities and Oral Health in Canada and the United States. Journal of Dental Research, 91, 865-870. https://doi.org/10.1177/0022034512455062

[14] McEwen, B.S. and Wingfield, J.C. (2003) The Concept of Allostasis in Biology and Biomedicine. Hormones and Behavior, 43, 2-15. https://doi.org/10.1016/S0018-506X(02)00024-7

[15] Steele, J., Shen, J., Tsakos, G., Fuller, E., Morris, S., Watt, R., Guarnizo-Herreño, C. and Wildman, J. (2015) The Interplay between Socioeconomic Inequalities and Clinical Oral Health. Journal of Dental Research, 94, 19-26.

https://doi.org/10.1177/0022034514553978

[16] Arevalo, S.P., Tucker, K.L. and Falcon, L.M. (2015) Beyond Cultural Factors to Understand Immigrant Mental Health: Neighbourhood Ethnic Density and the Moderating Role of Premigration and Post-Migration Factors. Social Science \& Medicine, 138, 91-100. https://doi.org/10.1016/j.socscimed.2015.05.040

[17] Baker, J., Mitchell, R. and Pell, J. (2013) Cross-Sectional Study of Ethnic Differences in the Utility of Area Deprivation Measures to Target Socioeconomically Deprived Individuals. Social Science \& Medicine, 85, 27-31. https://doi.org/10.1016/j.socscimed.2013.02.025

[18] Wu, B., Liang, J., Luo, H. and Furter, R. (2013) Racial and Ethnic Variations in Preventive Dental Care Utilization among Middle-Aged and Older Americans, 1999-2008. Frontiers in Public Health, 1, 65. https://doi.org/10.3389/fpubh.2013.00065 
[19] Reid, B.C., Hyman, J.J. and Macek, M.D. (2004) Race/Ethnicity and Untreated Dental Caries: The Impact of Material and Behavioral Factors. Community Dentistry and Oral Epidemiology, 32, 329-336. https://doi.org/10.1111/j.1600-0528.2004.00165.x

[20] Conway, D.I., Quarrell, I., McCall, D.R., Gilmour, H., Bedi, R. and Macpherson, L.M. (2007) Dental Caries in 5-Year-Old Children Attending Multi-Ethnic Schools in Greater Glasgow-The Impact of Ethnic Background and Levels of Deprivation. Community Dental Health, 24, 161-165.

[21] Bedi, R. and Elton, R.A. (1991) Dental Caries Experience and Oral Cleanliness of Asian and White Caucasian Children Aged 5 and 6 Years Attending Primary Schools in Glasgow and Trafford, UK. Community Dental Health, 8, 17-23.

[22] Lukes, S.M. and Miller, F.Y. (2002) Oral Health Issues among Migrant Farm Workers. Journal of Dental Hygiene, 76, 134-140.

[23] World Health Organization (1997) Oral Health Surveys: Basic Methods. 4th Edition, ORH/EPID, Geneva, 93.

[24] O'Leary, T.J., Drake, T.J.B. and Naylor, J.E. (1972) The Plaque Control Record. Journal of Periodontology, 43, 38. https://doi.org/10.1902/jop.1972.43.1.38

[25] Ainamo, J. and Bay, I. (1975) Problems and Proposals for Recording Gingivitis and Plaque. International Dental Journal, 25, 229-235.

[26] Chapple, I.L.C., Mealey, B.L., et al. (2018) Periodontal Health and Gingival Diseases and Conditions on an Intact and a Reduced Periodontium: Consensus Report of Workgroup 1 of the 2017 World Workshop on the Classification of Periodontal and Peri-Implant Diseases and Conditions. Journal of Clinical Periodontology, 45, S68-S77.

[27] Caton, J., Armitage, G., Berglundh, T., et al. (2018) A New Classification Scheme for Periodontal and Periimplant Diseases and Conditions-Introduction and Key Changes from the 1999 Classification. Journal of Clinical Periodontology, 45, S1-S8. https://doi.org/10.1111/jcpe.12935

[28] Papapanou, P.N., Sanz, M., et al. (2018) Periodontitis: Consensus Report of Workgroup 2 of the 2017 World Workshop on the Classification of Periodontal and Peri-Implant Diseases and Conditions. Journal of Clinical Periodontology, 45, S162-S170.

[29] Papapanou, P.N., Wennstrom, J.L. and Grondahl, K. (1989) A 10-Year Retrospective Study of Periodontal Disease Progression. Journal of Clinical Periodontology, 16, 403-411. https://doi.org/10.1111/j.1600-051X.1989.tb01668.x

[30] Papapanou, P.N. (1989) Patterns of Alveolar Bone Loss in the Assessment of Periodontal Treatment Priorities. Swedish Dental Journal. Supplement, 66, 1-45.

[31] Wolff, R.E., Wolff, L.F. and Michalowicz, B.S. (2009) A Pilot Study of Glycosylated Hemoglobin Levels in Periodontitis Cases and Healthy Controls. Journal of Periodontology, 80, 1057-1061. https://doi.org/10.1902/jop.2009.080664

[32] Reddy, M.S., Geurs, N.C., Jeffcoat, R.L., Proskin, H. and Jeffcoat, M.K. (2000) Periodontal Disease Progression. Journal of Periodontology, 71, 1583-1590. https://doi.org/10.1902/jop.2000.71.10.1583

[33] Neely, A.L., Holford, T.R., Loe, H., Anerud, A. and Boysen, H. (2001) The Natural History of Periodontal Disease in Man. Risk Factors for Progression of Attachment Loss in Individuals Receiving No Oral Health Care. Journal of Periodontology, 72, 1006-1015. https://doi.org/10.1902/jop.2001.72.8.1006

[34] Bergstrom, J., Eliasson, S. and Dock, J. (2000) A10-Year Prospective Study of To- 
bacco Smoking and Periodontal Health. Journal of Periodontology, 71, 1338-1347. https://doi.org/10.1902/jop.2000.71.8.1338

[35] Elter, J.R., Beck, J.D., Slade, G.D. and Offenbacher, S. (1999) Etiologic Models for Incident Periodontal Attachment Loss in Older Adults. Journal of Clinical Periodontology, 26, 113-123. https://doi.org/10.1034/j.1600-051X.1999.260209.x

[36] Oliver, R.C., Brown, L.J. and Loe, H. (1998) Periodontal Diseases in the United States Population. Journal of Periodontology, 69, 269-278. https://doi.org/10.1902/jop.1998.69.2.269

[37] Borrell, L.N., Burt, B.A., Gillespie, B.W., Lynch, J. and Neighbors, H. (2002) Periodontitis in the United States: Beyond Black and White. Journal of Public Heath Dentistry, 62, 92-101. https://doi.org/10.1111/j.1752-7325.2002.tb03428.x

[38] Brown, L.F., Beck, J.D. and Rozier, R.G. (1994) Incidence of Attachment Loss in Community-Dwelling Older Adults. Journal of Periodontology, 65, 316-323. https://doi.org/10.1902/jop.1994.65.4.316

[39] Idrees, M.M., Azzeghaiby, S.N., Hammad, M.M. and Kujan, O.B. (2014) Prevalence and Severity of Plaque-Induced Gingivitis in a Saudi Adult Population. Saudi Medical Journal, 35, 1373-1377.

[40] Zhang, J., Xuan, D., Fan, W., Zhang, X., Dibart, S., De Vizio, W., et al. (2010) Severity and Prevalence of Plaque-Induced Gingivitis in the Chinese Population. Compendium of Continuing Education in Dentistry, 31, 624-629. https://doi.org/10.1093/carcin/bgp323

[41] Burt, B. (2005) Research, Science and Therapy Committee of the American Academy of Periodontology. Position Paper: Epidemiology of Periodontal Diseases. Journal of Periodontology, 76, 1406-1419.

[42] Tonetti, M.S.G.H. and Kornman, K.S. (2018) Staging and Grading of Periodontitis: Framework and Proposal of a New Classification and Case Definition. Journal of Clinical Periodontology, 45, S149-S161. https://doi.org/10.1111/jcpe.12945

[43] Armitage, G.C. (1995) Clinical Evaluation of Periodontal Diseases. Periodontology 2000, 7, 39-53. https://doi.org/10.1111/j.1600-0757.1995.tb00035.x

[44] Hansen, B.F., Gjermo, P. and Bergwitz-Larsen, K.R. (1984) Periodontal Bone Loss in 15-Year-Old Norwegians. Journal of Clinical Periodontology, 11, 125-131. https://doi.org/10.1111/j.1600-051X.1984.tb00840.x

[45] Gjermo, P., Bellini, H.T., Pereira Santos, V., Martins, J.G. and Ferracyoli, J.R. (1984) Prevalence of Bone Loss in a Group of Brazilian Teenagers Assessed on Bite-Wing Radiographs. Journal of Clinical Periodontology, 11, 104-113. https://doi.org/10.1111/j.1600-051X.1984.tb00838.x

[46] Hansen, B.F., Gjermo, P., Bellini, H.T., Ihanamaki, K. and Saxen, L. (1995) Prevalence of Radiographic Alveolar Bone Loss in Young Adults, a Multinational Study. International Dental Journal, 45, 54-61.

[47] Peeran, S.W., Singh, A.J., Alagamuthu, G., Peeran, S.A. and Naveen Kumar, P.G. (2012) Periodontal Status and Risk Factors among Adults of Sebha City (Libya). International Journal of Dentistry, 2012, Article ID: 787502. https://doi.org/10.1155/2012/787502

[48] Demmer, R.T., Kocher, T., Schwahn, C., Völzke, H., Jacobs, D.R. and Desvarieux, M. (2008) Refining Exposure Definitions for Studies of Periodontal Diseases and Systemic Disease Associations. Community Dentistry and Oral Epidemiology, 36, 493-502. https://doi.org/10.1111/j.1600-0528.2008.00435.x

[49] Lösche, W., Karapetow, F., Pohl, A., Pohl, C. and Kocher, T. (2000) Plasma Lipid 
and Blood Glucose Levels in Patients with Destructive Periodontal Disease. Journal of Clinical Periodontology, 27, 537-541. https://doi.org/10.1034/j.1600-051x.2000.027008537.x

[50] Schulte, W., d'Hoedt, B., Lukas, D., Maunz, M. and Steppeler, M. (1992) Periotest for Measuring Periodontal Characteristics-Correlation with Periodontal Bone Loss. Journal of Periodontal Research, 27, 184-190. https://doi.org/10.1111/j.1600-0765.1992.tb01667.x

[51] Demirel, K., Gür, H., Meriç, H. and Sevük, C. (1997) Damping Characteristics of Teeth with Periodontal Breakdown: Correlation of Mobility Meter Values with Bone and Attachment Loss. Journal of Periodontology, 68, 166-171.

https://doi.org/10.1902/jop.1997.68.2.166

[52] Kerdvongbundit, V. and Wikesjö, U.M.E. (2002) Prevalence and Severity of Periodontal Disease at Mandibular Molar Teeth in Smokers with Regular Oral Hygiene Habits. Journal of Periodontology, 73, 735-740.

https://doi.org/10.1902/jop.2002.73.7.735

[53] Feldman, R.S., Bravacos, J.S. and Rose, C.L. (1983) Association between Smoking Different Tobacco Products and Periodontal Disease Indexes. Journal of Periodontology, 54, 481-487. https://doi.org/10.1902/jop.1983.54.8.481

[54] Pontoriero, R., Nyman, S. and Lindhe, J. (1988) The Angular Bony Defect in the Maintenance of the Periodontal Patient. Journal of Clinical Periodontology, 15, 200-204. https://doi.org/10.1111/j.1600-051X.1988.tb01570.x

[55] Borrell, L.N., Burt, B.A., Neighbors, H.W. and Taylor, G.W. (2004) Social Factors and Periodontitis in an Older Population. American Journal of Public Health, 94, 748-754. https://doi.org/10.2105/AJPH.94.5.748

[56] Batra, P., Saini, P. and Yadav, V. (2020) Oral Health Concerns in India. Journal of Oral Biology and Craniofacial Research, 10, 171-174. https://doi.org/10.1016/j.jobcr.2020.04.011

[57] Goyal, R.C., Sachdeva, N.L. and Somasundaram, K.V. (1994) Oral Health Status of Rural Community in Western Maharashtra. Indian Journal of Preventive \& Social Medicine, 25, 137-145.

[58] Albandar, J.M. (2014a) Aggressive and Acute Periodontal Diseases. Periodontology 2000, 65, 7-12. https://doi.org/10.1111/prd.12013

[59] Susin, C., Haas, A.N. and Albandar, J.M. (2014) Epidemiology and Demographics Of aggressive Periodontitis. Periodontology 2000, 65, 27-45.

https://doi.org/10.1111/prd.12019 